\title{
Optical investigations of microwave induced synthesis of zinc oxide thin-film
}

\author{
AkHalakur Rahman Ansari ${ }^{1}$, Shahir Hussain ${ }^{2, *}$, Mohd. Imran ${ }^{3}$, \\ Attien A. Al-Ghamdi ${ }^{1}$, Mohammed RehaAn Chandan ${ }^{4}$ \\ ${ }^{1}$ Centre of Nanotechnology, King Abdulaziz University, Jeddah 21589, Saudi Arabia \\ ${ }^{2}$ Electrical Engineering Department, Faculty of Engineering, Jazan University, P.O. Box 706, Jazan 45142, Saudi Arabia \\ ${ }^{3}$ Chemical Engineering Department, Faculty of Engineering, Jazan University, P.O. Box 706, Jazan 45142, Saudi Arabia \\ ${ }^{4}$ Chemical Engineering Department, School of Civil and Chemical Engineering, VIT University, Vellore, TN 632 014, India
}

In this article, $\mathrm{ZnO}$ thin-film deposition on a glass substrate was done using microwave induced oxygen plasma based CVD system. The prepared thin-films were tested in terms of crystallinity and optical properties by varying the microwave power. The effect of power variation on the morphology and size of final products was carefully investigated. The crystal structure, chemical composition and morphology of the final products were characterized using X-ray diffraction (XRD), scanning electron microscopy (SEM), UV-Vis spectroscopy, Raman spectroscopy and photoluminescence (PL). This technique confirmed the presence of hexagonal $\mathrm{ZnO}$ nanocrystals in all the thin-films. The minimum crystallite grain size as obtained from the XRD measurements was $\sim 9.7 \mathrm{~nm}$ and the average diameter was $\sim 18 \mathrm{~nm}$.

Keywords: ZnO; thin film; microwave CVD; XRD; SEM; UV; PL; Raman spectroscopy

\section{Introduction}

Nanotechnology has the prospective to produce many devices with different applications in the fields of medicine [1], electronics [2], and energy production [3]. $\mathrm{ZnO}$ semiconductor may be a good alternative as it can exhibit several attractive properties, such as a higher electronic mobility [4], large exciton binding energy (60 meV). Due to these properties $\mathrm{ZnO}$ became a promising material for electronic and optoelectronic applications such as gas sensors, solar cells, liquid crystal displays (LCD), heat mirrors, surface acoustic wave devices, etc. [5]. The increased surface area-to-volume ratios and quantum size effects made these materials potential candidates for device applications. These applications need stable electrical parameters of zinc oxide, possibly achieved without any post-growth treatment of the deposited $\mathrm{ZnO}$ layers. Many methods

*E-mail: shahir.jmi@gmail.com have been described in the literature for synthesis of $\mathrm{ZnO}$ nanostructures, such as chemical vapor deposition [6], thermal oxidation [7], molecular beam epitaxy [8], and pulse laser deposition [9]. In chemical vapor deposition, radiofrequency and microwave techniques are commonly used. The microwave method is better than the radio-frequency method because of its symmetry, plasma stability and sensitivity of oxidation crystallization process [10].

$\mathrm{ZnO}$ nanoparticles thin-film was synthesized using a simple microwave based CVD technique. The obtained film properties were controlled by changing different parameters of deposition system such as substrate temperature, deposition time, microwave power and pressure. In this article, we report microwave power dependent synthesis of $\mathrm{ZnO}$ thin-film on the glass substrate by microwave based CVD system. Nano-structural, optical, surface morphological properties were measured giving insight into the variation of such properties with microwave power. 


\section{Experimental}

\section{1. $\mathrm{ZnO}$ thin-film preparation}

Zinc acetate dihydrate, $\mathrm{Zn}\left(\mathrm{O}_{2} \mathrm{C}_{2} \mathrm{H}_{3}\right)_{2} \cdot 2 \mathrm{H}_{2} \mathrm{O}$ purchased from Semikem and ethanol solution (99.5\% purity) procured from Sigma Aldrich were used as precursors for the preparation of deposition solvent. Ethanolic solution of zinc acetate of $0.16 \mathrm{M}$ concentration was prepared by sonication. This solution was put in an ultrasonicator bath for 5 hours and the resultant solution was obtained. Before the deposition process, glass substrates (Sail Brand, Microscope Slides, China, $25.4 \mathrm{~mm} \times 70.2 \mathrm{~mm} \times 1 \mathrm{~mm})$ were cleaned by a standard cleaning procedure. The glass substrate was spin coated at $2000 \mathrm{rpm}$ for 2 minutes with the prepared solution to obtain a uniform layer of the solution. Microwave based plasma deposition unit (HPMS-2020 Microwave Plasma CVD, MPCVD, Chengdu Newman-Hueray Microwave Tech. Co., Ltd., China) equipped with (HMG-2020S) $2 \mathrm{~kW}$ microwave power source was used for synthesis of $\mathrm{ZnO}$ thin-films [11]. The spin coated glass substrate was put on a substrate holder inside the chamber. The chamber was evacuated by a rotary pump and a vacuum of $5 \mathrm{kPa}$ was maintained. $\mathrm{O}_{2}$ purging was done at a rate of $80 \mathrm{sccm}$ and the pressure was maintained using a needle valve. The microwave power was varied from $400 \mathrm{~W}$ to $1200 \mathrm{~W}$ and was applied to the samples for 10 minutes to create $\mathrm{O}_{2}$ plasma and form a thin-film. The samples synthesized at $400 \mathrm{~W}, 800 \mathrm{~W}$ and $1200 \mathrm{~W}$ microwave power were designated as S1, S2 and S3, respectively. After the deposition process, the system was left for $10 \mathrm{~min}$ to cool down to room temperature. $\mathrm{ZnO}$ thin-film was successfully obtained on the glass substrate and ethanol was evaporated after plasma exposure.

\subsection{Characterization}

Optical absorption spectra of $\mathrm{ZnO}$ thin-films were measured using a UV-Vis spectrophotometer (PerkinElmer Lamba 750) and Raman spectroscopy (LabRM HR and Horiba). The Raman measurements were carried out at $532 \mathrm{~nm}$ wavelength, laser excitation was performed at room temperature and atmospheric pressure. Scanning electron microscope (JEOL) was used to capture the surface morphological images of $\mathrm{ZnO}$ particles. The thin-film samples were coated with thin film of gold using sputtering before SEM analysis. $X$-ray diffraction pattern was recorded using an $\mathrm{X}$-ray diffractometer (Ultima IV) with $\mathrm{CuK} \alpha$ radiation of wavelength $\lambda=0.15406 \mathrm{~nm}$ in the scan range of $2 \theta=20^{\circ}$ to $90^{\circ}$. The photoluminescence (PL) spectrum of the $\mathrm{ZnO}$ nanoparticles was obtained using a spectrofluorophotometer (RF-5301, Shimadzu).

\section{Results and discussion}

\subsection{Structural properties of $\mathrm{ZnO}$ thin- films}

X-ray diffraction analysis was carried out to study the crystal quality and orientation of the synthesized $\mathrm{ZnO}$ thin-films. $\mathrm{X}$ ray diffraction patterns of samples S1, S2 and S3 are shown in Fig. 1. The broad peak in the XRD patterns reveals that very small nanocrystals are present in the samples [12]. The interplanar spacing $\left(\mathrm{d}_{\mathrm{h} \mathrm{k} 1}\right)$ calculated from XRD and JCPDS Data Card and corresponding (h k l) values are summarized in Table 1 . The sharp and narrow diffraction peaks are the evidence of good crystalline quality of the $\mathrm{ZnO}$ thin-films. The reflection peaks at $\left(\begin{array}{lll}1 & 0 & 0\end{array}\right),\left(\begin{array}{lll}0 & 0 & 2\end{array}\right),\left(\begin{array}{lll}1 & 0 & 1\end{array}\right)$, $\left(\begin{array}{lll}1 & 1 & 0\end{array}\right),\left(\begin{array}{lll}1 & 0 & 3\end{array}\right)$ and $\left(\begin{array}{lll}1 & 1 & 2\end{array}\right)$ are indicative of the hexagonal wurtzite $\mathrm{ZnO}$ nanostructure [13].

For films deposited at $400 \mathrm{~W}, 800 \mathrm{~W}$ and $1200 \mathrm{~W},\left(\begin{array}{lll}1 & 0 & 1\end{array}\right)$ peak of $\mathrm{ZnO}$ was observed and the intensity of this peak was found to be increasing with increasing microwave power. Furthermore, the height of $\left(\begin{array}{lll}0 & 0 & 2\end{array}\right)$ peaks was increased at higher microwave power (greater than $400 \mathrm{~W}$ ). To determine the crystallite size D of the synthesized films, the full width at half maximum (FWHM) of the diffraction peaks and Scherrer formula were used:

$$
D=(0.94 \lambda) /(F W H M \cos \theta)
$$

The crystallite size was estimated from $\left(\begin{array}{lll}1 & 0 & 1\end{array}\right)$ peak, since it appeared in all the samples. From Table 1, we found that the FWHM of $\left(\begin{array}{lll}0 & 0 & 2\end{array}\right)$ peaks and the crystallite size vary with applied 


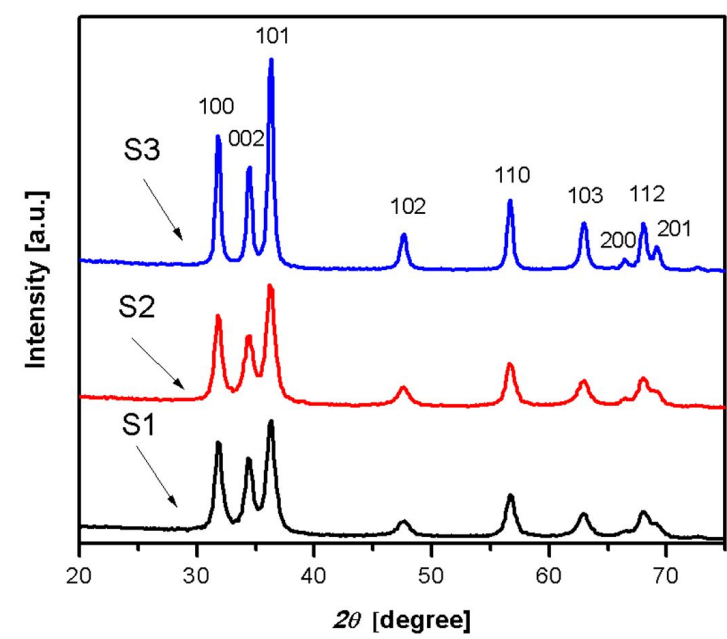

Fig. 1. X-ray diffraction (XRD) patterns of the prepared $\mathrm{ZnO}$ nanoparticles of sample S1, S2 and S3.

microwave power. The diffraction peak sharpness increases with respect to the microwave power and FWHM values are reduced with increasing power. Moreover, (llll $\left.\begin{array}{lll}1 & 0 & 1\end{array}\right)$ plane has the strongest line for all employed microwave powers. As the grain size is inversely proportional to the value of FWHM, the nanoparticle size should increase with increasing microwave power as seen in SEM image (Fig. 2) [14]. A degradation of the structure with alkali ions from the glass substrate may be a cause of the increment in the particle size [15].

It is also known from the literature that with an increase in microwave power, oxygen plasma temperature increase results in an increase in zinc acetate solution temperature on glass substrate. This increase in temperature enhances the tendency of the $\mathrm{ZnO}$ nuclei to aggregate and thus we observe an increase in particle size with the increase of microwave power [11]. This also leads to different morphologies and structures of $\mathrm{ZnO}$ thin films.

SEM images shown in Fig. 2 contain the films deposited on glass substrates showing a dense packing of assembled particles. The obtained films are transparent and have a homogeneous surface. The surface consists of spherical grains having an average size from $9.7 \mathrm{~nm}$ to $18 \mathrm{~nm}$ (Fig. 2) measured using ImageJ software. The particles size is then a function of the precursor solution concentration and microwave power.

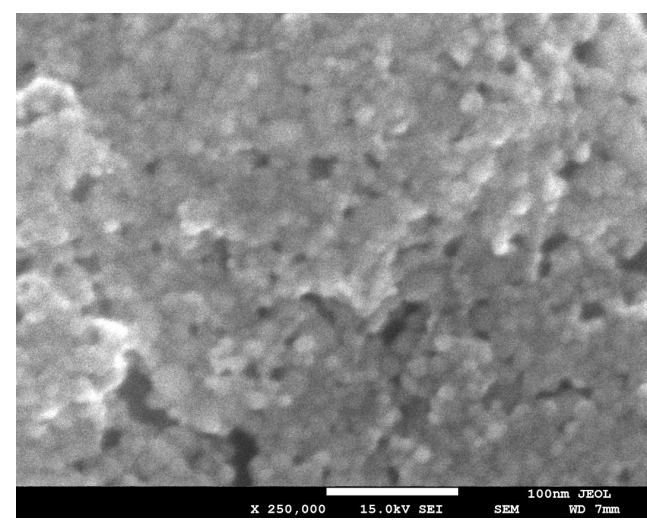

(a)

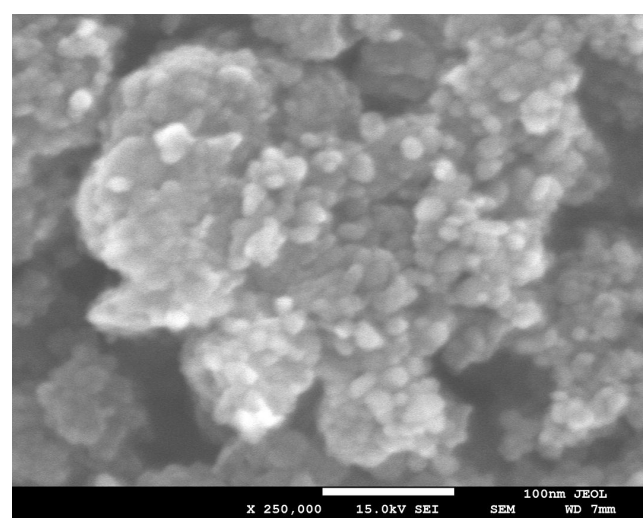

(b)

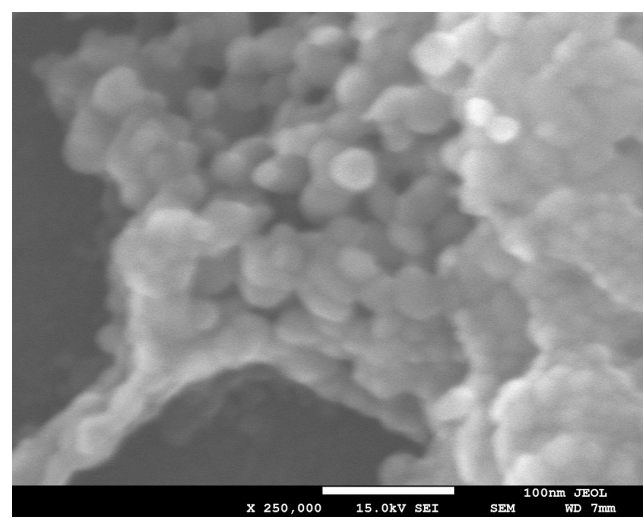

(c)

Fig. 2. SEM images of sample (a) S1, (b) S2 and (c) S3.

The average grain size for sample S1 was calculated as $10 \mathrm{~nm}$, while for samples S2 and S3 the sizes were found to be $11 \mathrm{~nm}$, and $18 \mathrm{~nm}$, respectively. During synthesis process, agglomeration of nanoparticles was the major problem which was due to the high surface energy 
Table 1. Summary data of XRD results of samples (S1, S2 and S3)

\begin{tabular}{|c|c|c|c|c|c|c|}
\hline Sample & No. & 2-theta $[\theta]$ & $\mathrm{d}[\AA]$ & FWHM [ $\theta]$ & Size $[\mathrm{nm}]$ & Phase name \\
\hline \multirow{3}{*}{ S1 } & 1 & 31.7681 & 2.81441 & 0.7222 & 11.94 & $\mathrm{ZnO}\left(\begin{array}{lll}1 & 0 & 0\end{array}\right)$ \\
\hline & 2 & 34.3884 & 2.60573 & 0.8937 & 9.71 & $\mathrm{ZnO}\left(\begin{array}{lll}0 & 0 & 2\end{array}\right)$ \\
\hline & 3 & 36.2579 & 2.47554 & 0.8606 & 10.15 & $\mathrm{ZnO}\left(\begin{array}{lll}1 & 0 & 1\end{array}\right)$ \\
\hline \multirow{3}{*}{ S2 } & 1 & 31.7967 & 2.81194 & 0.7233 & 11.93 & $\mathrm{ZnO}\left(\begin{array}{lll}1 & 0 & 0\end{array}\right)$ \\
\hline & 2 & 34.3858 & 2.60591 & 0.7866 & 11.04 & $\mathrm{ZnO}\left(\begin{array}{lll}0 & 0 & 2\end{array}\right)$ \\
\hline & 3 & 36.2889 & 2.47349 & 0.8602 & 10.15 & $\mathrm{ZnO}\left(\begin{array}{lll}1 & 0 & 1\end{array}\right)$ \\
\hline \multirow{3}{*}{ S3 } & 1 & 31.8072 & 2.81104 & 0.4721 & 18.27 & $\mathrm{ZnO}\left(\begin{array}{lll}1 & 0 & 0\end{array}\right)$ \\
\hline & 2 & 34.4351 & 2.60229 & 0.4823 & 18.01 & $\mathrm{ZnO}\left(\begin{array}{lll}0 & 0 & 2\end{array}\right)$ \\
\hline & 3 & 36.2767 & 2.4743 & 0.5228 & 16.7 & $\mathrm{ZnO}\left(\begin{array}{lll}1 & 0 & 1\end{array}\right)$ \\
\hline
\end{tabular}

of the nanoparticles [16]. The grain size changed randomly with increasing microwave power, which agrees well with the XRD analysis.

\subsection{Optical properties of $\mathrm{ZnO}$ films}

Raman spectroscopy is based on inelastic scattering of monochromatic light, broadly used for qualitative and quantitative studies with respect to electron-phonon interaction. With excitation at $532 \mathrm{~nm}$, we observe several peaks at $327 \mathrm{~cm}^{-1}$, $433 \mathrm{~cm}^{-1}$ and $566 \mathrm{~cm}^{-1}$ (Fig. 3), which are attributed to optical phonons of $\mathrm{ZnO}$. The most intense and narrow peak at $433 \mathrm{~cm}^{-1}$ arises from first-order Raman scattering by the E2 phonons of $\mathrm{ZnO}$, which ensures the good crystal quality [17]. The second order modes at $331 \mathrm{~cm}^{-1}$, $531 \mathrm{~cm}^{-1}$ and $1150 \mathrm{~cm}^{-1}$ disappeared from the spectra, which reflects a decrease in the crystallization quality compared to the bulk. Dominant peaks at $433 \mathrm{~cm}^{-1}$, which are commonly detected in the wurtzite structure $\mathrm{ZnO}$, are attributed to the high E2 modes of non-polar optical phonons, respectively. The Raman spectra of the synthesized $\mathrm{ZnO}$ thinfilm exhibits a resolved peak at $433 \mathrm{~cm}^{-1}$ corresponding to high frequency $\mathrm{E} 2$ mode in $\mathrm{ZnO}$. This peak has high intensity in S3 sample, which was prepared at high microwave power.

Photoluminescence (PL) is a measure of spontaneous emission of light from a material under optical excitation which is mostly used for semiconductors. UV emission peaks are observed

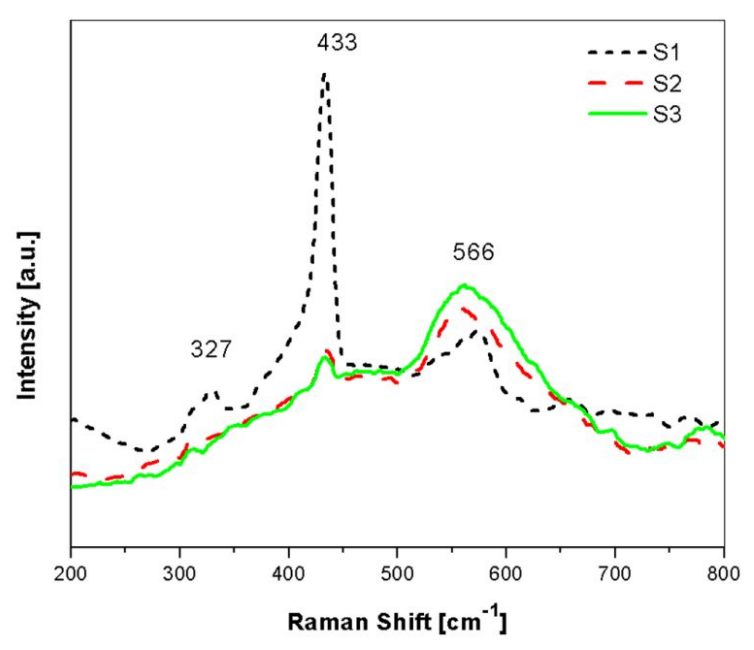

Fig. 3. Raman spectra of $\mathrm{ZnO}$ thin-film on glass substrates for different samples.

in all samples as shown in Fig. 4. These peaks are attributed to the free excitons recombination. It was suggested that appearance of the strong UV emission in the PL spectra is an indication of a good crystalline structure of the nanoparticles with excellent optical properties [17]. The observed UV emission appeared to broaden the peak with increasing microwave power. Intrinsic defects, surface modification and crystallization conditions are related to luminescence properties of $\mathrm{ZnO}$ film [18].

All the PL spectra for $\mathrm{ZnO}$ present two kinds of emission peaks: a UV emission centered 


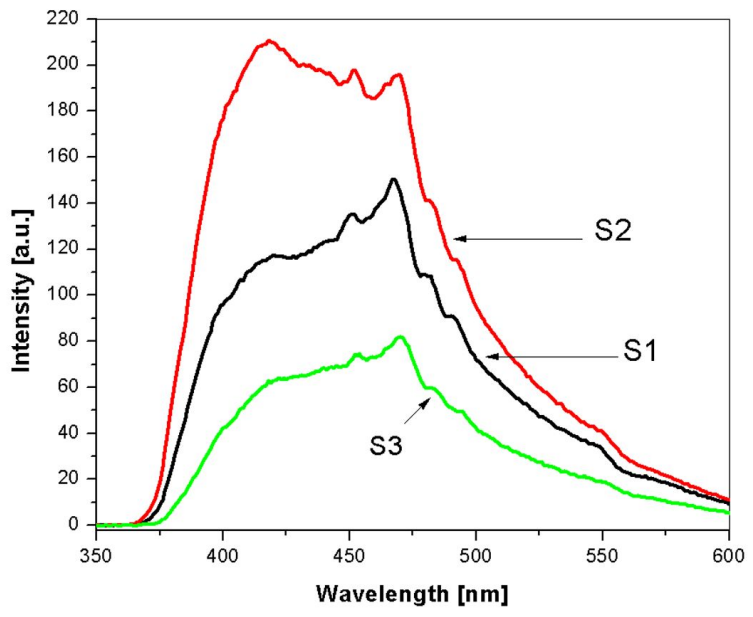

Fig. 4. Photoluminescence spectra of ZnO-thin-films on glass substrates.

at $\sim 380 \mathrm{~nm}$ to $390 \mathrm{~nm}$ and a wide visible emission, in blue and green regions, centered at $456 \mathrm{~nm}$ to $482 \mathrm{~nm}$ and $513 \mathrm{~nm}$ to $525 \mathrm{~nm}$, respectively. The UV emission band in $\mathrm{ZnO}$ nanostructures occurs due to the recombination of free excitons $[19,20]$ acceptor bound excitons [21] or donor-bound excitons [22].

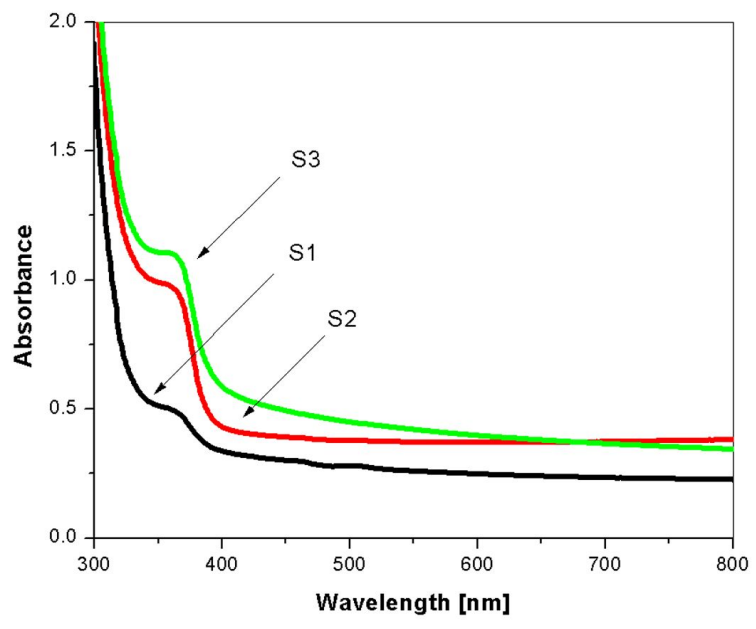

Fig. 5. UV-Vis absorption spectra of $\mathrm{ZnO}$ thin-films.

The UV-Vis absorption spectra of the $\mathrm{ZnO}$ thinfilm prepared at different microwave powers are shown in Fig. 5. An absorption peak is observed in each sample at $360 \mathrm{~nm}$ to $380 \mathrm{~nm}$, which is a characteristic band for pure $\mathrm{ZnO}$ [23].
No other peak exists in the spectrum which confirms that the synthesized products are $\mathrm{ZnO}$ only. Interestingly, an obvious red shift in the absorption edge was observed for the products obtained at different microwave powers. This may have happened due to the changes in their morphologies, particle size and surface microstructures [24]. S3 sample exhibits a strong absorption at $358 \mathrm{~nm}, \mathrm{~S} 2$ at $362 \mathrm{~nm}$, and S1 at $366 \mathrm{~nm}$. It is observed that absorption is shifted to higher wavelength; this shifting occurs due to the increase in grain size and decrease in bandgap. It is known that the $\mathrm{ZnO}$ particles, which exhibit absorption at higher wavelength in the UV-Vis spectrum, have larger particle size [25]. Thus, the UV-Vis results are in agreement with the $\mathrm{XRD}$ results in $\mathrm{ZnO}$ particles size prediction.

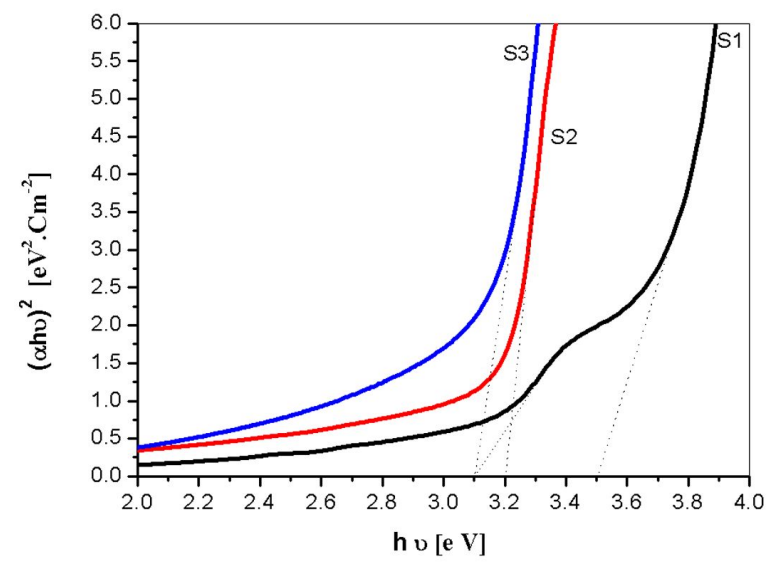

Fig. 6. Plots of $(\alpha \mathrm{h} v)^{2}$ vs. photon energy hv for $\mathrm{ZnO}$ thin films.

The optical band gap of the films was determined by applying the Tauc model [25] and the Davis et al. model [26] in the high absorbance region:

$$
\alpha h v=K\left(h v-E_{g}\right)^{m}
$$

where $\mathrm{h} v$ is the photon energy, $\mathrm{E}_{\mathrm{g}}$ is the optical band gap, $\mathrm{K}$ is a constant and $\mathrm{m}$ depends on the kind of optical transition that prevails. Particularly, for $m=1 / 2$, a good linearity was observed for the direct allowed transition. The band gap energy of the samples was measured by extrapolating the linear portion of the graph [27], as shown in Fig. 6. 
It can be concluded that with the increase in the microwave power from $400 \mathrm{~W}$ to $1200 \mathrm{~W}$, the optical band gap red shifts from $3.5 \mathrm{eV}$ to $3.10 \mathrm{eV}$. The effect of red shift of the band gap can also be related to structural morphology, particle size and surface microstructure [24].

\section{Conclusions}

High-density $\mathrm{ZnO}$ nanoparticles thin-films were synthesized via a microwave-assisted CVD method using zinc acetate and ethanolic solution as reactants without the need of a post-synthesis treatment. The products were characterized by XRD, SEM, UV-Vis absorption, Raman and PL. The deposition technique used was simple and cost effective. Precise control of precursor quantity, plasma exposure time and microwave power is required for repeatability and uniformity of thin-film. XRD results show that the film exhibits a single-crystalline wurtzite hexagonal structure. PL spectra of the $\mathrm{ZnO}$ thin-film on glass substrate show a strong UV emission band located at $358 \mathrm{~nm}$, which is ascribed to the near-band-edge emission. The band gap of $\mathrm{ZnO}$ has decreased with an increase in microwave power. An increase in grain size was observed with an increase in microwave power because their absorption edge was shifted to higher wavelength. The successful synthesis of $\mathrm{ZnO}$ by microwave assisted CVD could provide a crystalline zinc oxide thin-film with a high absorption and grain sizes of $9.7 \mathrm{~nm}$ to $18 \mathrm{~nm}$ that depend on the microwave power.

\section{References}

[1] Buot F.A., Phys Rep., 234(1993), 73.

[2] HuAng S., SCHLiChthörl G., NoziK A., Grätzel M., Frank A., J. Phys. Chem. B, 101 (1997), 2576.

[3] Lu L., Li R., FAn K., PEng T., Sol. Energy, 84 (2010), 844.

[4] Zhang H., Chen B., Jiang H., Wang C., Wang H., WANG X., Biomaterials, 32 (2011), 1906.

[5] Chopra L., Major S., Pandya D.K., Rastogi R.S., VANKAR V.D., Thin Solid Films, 1021 (1983), 1.
[6] Zang C.H., LiU Y.C., ZhaO D.X., Zhang Y.S., Physica B, 404 (2009), 315.

[7] LEE J.S., ISLAM M.S., KIM S., Sensor. Actuat. BChem., 126 (2007), 73.

[8] LiUa Y.L, LiUa Y.C., LiUb Y.B., Shena D.Z., Lua Y.M., Zhanga J.Y., Fana X.W., Solid State Commun., 138 (2006), 521.

[9] Ismail L.Z., Youssif M.I., Moneim H.M.A., Mater. Chem. Phys., 76(2002), 69.

[10] Sun Y., Fuge G.M., Ashfold M.N.R., Chem. Phys. Lett., 396 (2004), 21.

[11] Al-GaAshani R., Radiman S., TABet N., Daud A.R., Mater. Chem. Phys., 125 (2011) 846.

[12] Anitha S.N., JaYAKumari I., J. Nanosci. Nanotechno., 1 (2015), 26.

[13] Sahoo T., Kim M., Lee M.H., Jang L.W., JeON J.W., Kwak J.S., Ko I.Y., LeE I.H., J. Alloy. Compd., 491 (2010), 308.

[14] AzarofF L.V., Elements of X-Ray Crystallography, McGraw Hill, New York, 1968.

[15] VAnheerden J.L., Swanepoel R., Thin Solid Films, 299 (1997), 72.

[16] Hong R.Y., QIan J.Z., CaO J.X., Powder Technol., 163 (2006), 160.

[17] Zhang R., Yin P.G., Wang N., Guo L., Solid State Sci., 11 (2009), 865.

[18] Aadila A., AfaAh A.N., Asib N.A.M., MaHMUd M.R., AlRoKayan S.A.H., Khan H.A., MoHAMED R., Rusop M., Khusaimi Z., Mater. Sci. Eng. $B-A d v$., 83 (2015), 012007.

[19] Wong E.M., Searson P.C., Appl. Phys. Lett., 74 (1999), 2939.

[20] Mahamuni S., Borgohain K., Bendre B.S., LePPert V.J., Risbud S.H., J. Appl. Phys., 85 (1999), 2861.

[21] Fonoberov V.A., Balandin A.A., Appl. Phys. Lett., 85 (2004), 5971.

[22] LiU Y.L., LiU Y.C., FenG W., Zhang J.Y., LU Y.M., Shen D.Z., FANS X.W., WANG D.J., ZHAO Q.D., J. Chem. Phys., 122 (2005), 174703.

[23] Chieng B.W., Loo Y.Y., Mater. Lett., 73 (2012), 78.

[24] Zak A.K., Abrishami M.E., Abdmajid W.H., $C e-$ ram. Int., 37 (2011), 393.

[25] TAUC J., Amorphous and Liquid Semiconductors Plenum, Springer, London, 1974.

[26] Davis E.A., Mott N.F., Philos. Mag., 22 (1970), 903.

[27] Kumar S.S., Venkateswarlu P., Rao V.R., RaO G.N., Int. Nano Lett., 3(2013), 30.

Received 2017-09-12

Accepted 2018-03-29 